read a French one only with difficulty. These young men have spent many school years during which the study of Latin and Greek absorbed about one-third or one-fourth their total available study hours. What have they got for it? They cannot read a Latin author or a Greek author at sight. It is true that without their Latin they would not have attained the degree of the University of Dublin. The pro-classic says their minds are the better for it. Well, I freely admit that much mental training was involved, but I do not admit that a sound study of French and German would not have done for them just as much-nay, more.

The reproach that many students fail as research workers, while it has some foundation in fact, is not a fair one, for it ignores the educational value of even elementary research. I believe the outlook of a student who has carried out one single research of an elementary kind is different from that of one whose outlook is derived solely from the text-book and the examination. He learns first-hand the mental point of view of the investigator. He gets ideas of scientific truth and of the legion of errors which lie in wait around it as may in no other way be acquired. $\mathrm{He}$ sees the plausible, prima facie conclusion break down under the control experiment or in the light of the inexorable requirements of other participating laws of Nature. A new conception of the use of mathematical analysis and of careful observation is created in his mind. More generally he learns the necessity of "thinking round" his subject.

These things he learns in some degree even if he is only of average capabilities. If he is one of the higher spirits the interest of the work seizes on him and calls out every power, latent and developing, wherewith he is endowed. These higher spirits work out their own destiny. I shall not dwell on the ways of genius, but rather upon research as an instrument in the education of less gifted minds. I turn, therefore, to the interesting question: "Is it possible to teach research successfully?" To teach its methods and its spirit to the average student, whether of science or of the "humanities"?

The answer I would give unhesitatingly is "Yes." I would be careful to define that this does not imply the genesis of an original thinker from ordinary material. But it implies just as much as when we say we can teach students mathematics.

I plead, therefore, for lectures in our universities devoted exclusively to studies in research, and I would admit to these lectures students of both junior and senior standing, i.e. the beginners in science as well as those working for the Ph.D. as now instituted in all British universities.

Of course, I am not now referring to systematic lectures in this or that branch of science. These are essential to the training of the average student. mean something different. I would define research lectures as mainly relating to the professor's own experience and to that of his assistants and co-workers, each worker contributing one or more lectures to the university course in research. Their subject-matter would relate to the objects aimed at by the research, the difficulties attending the work, and how they were surmounted. Such discourses might be supplemented by others of an historical or retrospective character. These might in some cases be delivered by honours students, and would refer to classic researches of the great masters. For recounting these, experimental illustrations should be given. The inspiration to be derived from such retrospective studies will be known to all who have read the original memoirs of great investigators. There need be no extra call upon the professor's time. He would simply substitute these for part of his existing routine lecture work.

The professor is at present too much tied down by routine courses. There is a sort of idea prevalent that it is not fair to his class that he should tell them of his own work, but that this should rather be kept for the academy and for the outside world. Well, I think it is fair; and I believe that with reasonable usage the best thing he can do for his class is to tell them of his own work. If this were admitted in high quarters it would be more often carried out. I can imagine nothing more stimulating than a few lectures each term on the work progressing in the laboratory of the professor and his coworkers, for not only is the student brought into touch with the making of knowledge, he is also sure to receive the story in the language of fresh and enthusiastic interest.

I am aware that occasionally and at scientific associations within the university such discourses are delivered. I would make them a part of the sessional work of the university. If not legally obligatory on the professor, it should be morally obligatory on him to contribute a few such lectures every term, or at least every session. I do not think it would impose additional labours on him. Fresh from his work, but little rearrangement would be required, and his facts would be ready marshalled in his memory. Nor would the telling of his ideas fail to react upon the lecturerto his benefit and to the elucidation of his subject.

The one central result aimed at is the presentation of research as something of paramount importance. It should stand for the highest goal of university effort, for, in truth, success in the making of knowledge is the crown of all human endeavour, and as such the student should be taught to regard it. Teach him this one great ethical truth, and whatever else he may accomplish or fail to accomplish in his student days, he will enter on his life's work an enlightened and a valuable citizen, not only of his own country, but also of the world.

\title{
International Exploration of the Upper Air.
}

\section{By C. J. P. CAve.}

\begin{abstract}
A MeEting of the International Commission for A the Exploration of the Upper Air was held at Bergen on the invitation of Prof. V. Bjerknes, president of the commission, in the week ending July 30 . The commission was appointed by the Meteorological Conference held at Paris in 1919 to continue the work, in connection with the International Meteorological Committee, which was carried on with marked success from 1896 until the beginning of the war, and with which is specially assaciated the names of the late Teisserenc de Bort, Rotch, and Assmann, under the presidency of Prof. Hergesell.
\end{abstract}

No. 2702 , vOL. 107]
The following countries were represented at Bergen : Belgium, Denmark, France, Great Britain, Holland and the Dutch East Indies, Italy, Japan, Norway, Spain, Sweden, and Switzerland; and the meetings were also attended by a number of prominent meteorologists from Norway and Sweden. The proceedings opened with a reception by the president and Mrs. Bjerknes at the Meteorological Office of the Geophysical Institute, and with a lecture by J. Bjerknes on recent advances in the study of the Polar front and its relation to a succession of cyclones. It was arranged that the morning sessions should be devoted 
to scientific communications presenting new points of view, and the afternoons to administrative details. This arrangement was disturbed in the course of the week in order to provide more time for administrative questions.

The sessions for scientific discussions were opened by a paper by Prof. V. Bjerknes giving theoretical explanations, on the basis of wave motion at the mutual boundary of two discontinuous media, of the series of phenomena which had been set out by his son, representing the result of observations upon the Polar front in cyclones. This was followed by a paper by Sir Napier Shaw on the structure of the atmosphere and its thermodynamics, to suggest a thermodynamic basis for the study of convection in the atmosphere, and the transformations of energy associated therewith. A paper by L. F. Richardson directed attention to the necessity for studying pilotballoon observations in relation to the continuity of mass, a subject which in spite of its importance has hitherto not received adequate treatment. Prof. van Everdingen gave an account of a method of obtaining regular observations of pressure, temperature, and humidity in the upper air by means of aeroplanes, using a balloon meteorograph with the usual clockwork drum; such observations had been carried out on upwards of 340 occasions in the past year at Soesterberg and other stations in Holland. S. Fujiwhara, of Tokyo, discussed turbulent movements which are to be observed in clouds, and their relation to eddies in water. Dr. W. van Bemmelen, of Java, gave an account of comprehensive results of great importance of observations of wind in the upper atmosphere up to 30 kilometres, obtained at the observatory at Batavia. H. Köhler, of Holdda, discussed the study of the condensation of water vapour in a cold atmosphere into ice crystals and supercooled water drops, and the effects which may be attributed to very small quantities of chlorides.

L. F. Richardson discussed the application of the geostropic principle to winds in the stratosphere. Dr. A. de Quervain, of Zurich, brought up proposals for the establishment of a geophvsical observatory at the terminus of the Jungfrau railway, at a height of 3600 metres, which received the cordial commendation of the meeting. P. Schereschewsky, of the Corps of Mines, Paris, explained the method of determining the winds in the upper air by means of sound-ranging applied to detonators carried by pilot balloons, a method which is applicable alike in clear and cloudy weather. R. Sekiguti, of the Observatory of Kobe, explained the application in forecasting of isobaric charts for the level of three kilometres. Col. L. Matteuzzi, director of the Meteorological Service of Italy, presented an atlas of the principal cloud forms. and explained a method of applying the periodicity of barometric oscillations to the anticipation of barometric distribution in the future. O. Devil, of Tromsø, described a new method of observing balloons and its application in forecasting. G. I. Taylor gave an account of the result of his investigation of turbulence in the atmosphere and its symmetric propagation in the three dimensions. M. Dongier discussed the observations of temperature and wind at the Eiffel
Tower and the discontinuities which they disclose. J. Bjerknes directed attention to the unique accumulation of observations of the upper air during the war which had been communicated to the president by the countries on both sides, and gave illustrations of the observations on selected occasions in the study of the method of the Polar front. P. Schereschewsky gave an account of some new methods of forecasting, and the proceedings of the meetings for scientific discussion were concluded with a paper by L. F. Richardson on ideal arrangements of stations on the map for the purpose of numerical computations for forecasting.

The business meetings were devoted largely to the development of a scheme for the collection, compilation, and publication of observations in the upper air on an international basis, in continuation, with such modifications as experience has suggested, of the international scheme which was agreed upon at Petrograd in 1904 and supported by subventions from Government organisations of nineteen countries. The outline of a proposal was agreed upon, and the president was requested to report it to the meeting of the International Meteorological Committee to be held in London in September. The commission adopted resolutions in favour of a geophysical observatory on the Jungfrau, and also appointed a subcommittee to deal with the question of the anomalies in the audibility of the sound of explosions, which was also the subject of a communication by Dr. de Quervain.

It was noticeable that the commission devoted the greater part of its attention to the mode of dealing with the observations of the upper air based upon the supposition that there should be twenty-four days in the year on which balloons for sounding the highest layers of the meteorological atmosphere, including the stratosphere, should be sent up in a sufficient number of countries to secure a general representation of the whole. At present the number of observations is extremely limited, and the reorganisation of the observations would need the support of meteorological institutes in many parts of the world. Beyond pointing out the urgent necessity for such observations over the sea, the technique of which had already been worked out by Teisserenc de Bort and the German meteorologists, but which had not become international in any sense, the commission confined itself to a general invitation to the meteorological organisations of the globe for co-operation on the international days.

An account of the proceedings of the meetings would be incomplete without reference to the hospitality of the citizens of Bergen. It will be remembered that the greater part of the inner town was destroyed by a disastrous fire five years ago, and it has not yet been rebuilt; all the hotel accommodation was required for tourists, and the delegates to the meeting were all entertained with cordial hospitality by the foreign Consuls and the citizens of Bergen, and also honoured by an official dinner given by the municipality, at which the Chief Burgomaster presided. The municipality also placed its ancient and picturesque Council House at the disposal of the commission for the meetings.

\section{A Small Brinell Hardness Testing Machine.}

H ARDNESS, as recent correspondence in NATURE H (vol. cvi., pp. 377, 440, 534, 599, 662, November, I920-January, I92I) has shown, is a subject of interest to both the engineer and the physicist. Whatever may be the exact physical significance of the term, there can be no doubt that measurements of this property, or NO. 2702 , VOL. IO7] group of properties, are of increasing practical importance. In the Brinell method of measuring hardness, as commonly applied, a steel ball of diameter about $\mathrm{I} \mathrm{cm}$. is applied to the surface of the test piece under a load of the order of $3000 \mathrm{~kg}$., and the size of the resulting impression is measured. In practice 